\title{
Reflexiones sobre la evangelización en la actualidad*
}

\author{
Jon Sobrino, \\ Centro de Reflexión Teológica, \\ San Salvador.
}

En este artículo queremos hacer algunas reflexiones sobre la evangelizacion en la actualidad. Para tratar adecuadamente el terna habría que tener en cuenta, sin duda, las nuevas realidades que de una u otra forma tienen que ver con el anuncio de una buena noticia: el género, las etnias, la ecología, el diálogo con las religiones. $\mathrm{Y}$ habría que abordar también, con creatividad, el tema de los evangelizadores: los laicos, en lo que insiste el cardenal Arns; los pobres, en lo que ya insistió Puebla. Aquí nos vamos a concentrar, sin embargo, en los problemas que podemos llamar perennes y que, por ello, también en la actualidad necesitan un tratamiento adecuado al momento en que vivimos.

En el análisis tenemos en cuenta dos criterios fundamentales. Uno es la persona y la misión de Jesús de Nazaretl, y otro es la realidad de las víctimas de este mundo. En el desarrollo del terna vamos a seguir el esquema de la Evangelii Nuntiandi de Pablo VI, historizándolo para la situación actual2. Huelga decir que no podemos abordar toda la problemática de la evangelización, sino sólo aquellos puntos que nos parecen importantes y a los que, quizás, podarnos aportar alguna luz desde nuestra situación.

* El presente articulo es la reelahoración de una ponencia que tuvo el autor en el Congreso de teología sobre Iglesia y evangelización, celebrado en Madrid del 4 al 8 Je septiembre de 1996.

I. Véase lo que escribimos en Jesucristo liberador, San Salvador, 1991, pp. 119-306.

2. Sobre la Evangelii Nuntiandi, véase nuestro escrilo "La evangelización como misión de la Iglesia", en Resurrección de la verdadera Iglesia, Santander, 1981, pp. 261308 . 


\section{La condición: ¿hay convicción de que hoy es posible una buena noticia?}

Primera proposición. Evangelizar es comunicar una buena noticia a los pobres. Este hecho objetivo presupone la convicción subjetiva de que existe una "buena noticia" que anunciar, lo cual es, precisamente, lo que está en crisis. Pero sin esa convicción y sin el talante de "buena noticia" desaparece, formalmente, la evangelización, se la reduce a indoctrinación en el mejor de los casos o a ideologización interesada en el peor de ellos.

La Evangelii Nuntiandi (n. 7) comienza con la afirmación de que Jesús es "el primer evangelizador", con lo cual, por trivial que parezca la observación, nos ofrece una vía segura para abordar el tema de la evangelización. Pues bien, lo primero que hay que decir de Jesús, el evangelizador, es que tiene la convicción subjetiva de que existe una buena noticia que anunciar $-y$ de que, por ello, su vida y inisión se constituyen al servicio de esa buena noticia.

Esto ha quedado claramente expresado en los sinóplicos en las dos palabras más centrales y auténticas suyas: basileia y abba, reino y Padre. Con ellas, Jesús no alirma, en directo, la verdad de una doctrina, sino que expresa ante todo la convicción de que existe una realidad buena que anunciar. "Tengo que anunciar la buena noticia del reino de Dios" (Lc 4, 43). "Cuando oren, llamen a Dios Padre" (Mt 6, 9).

Esla convicción, que aparece muy pronto, en su discurso inaugural en la sinagoga de Nazaret, según Lucas, y en su primer gran sermón, según Mateo, se mantiene a lo largo de toda su vida, aun en medio de oscuridades internas y de persecuciones externas, pues, escandalosamente, a quien anuncia la buena noticia a las victimas le sobreviene la persecución. Y la mantiene también a pesar de que el reino no llega ni el Padre lo salva de la muerte. $Y$ así, al parecer, Jesús en la última cena mantiene su convicción evangélica: pronto volverá a heber del cáliz con sus discípulos, "en el reino de Dios" (Lc 22, 18), y en la oración del huerto sigue Ilamando a Dios Abba (Mc 14, 36)3.

Baste esta breve referencia a Jesús para introducirnos en lo que nos parece ser hoy el problema fundamental de la evangelización. Si ésta no es formalmente comunicación de doctrina, ni de teología, o magisterio, o cánones - lo cual sí abunda-, entonces, la pregunta fundamental es si existe en la Iglesia la convicción de que es posible anunciar algo bueno de parte de Dios, algo que produzca gozo y esperanza, sin tener que caer en la rutina, la licción o el autoengaño.

3. Es difícil, si no imposible. conocer el estado de ánimo de Jesús durante su agonía en la cruz. Según Marcos y Mateo, Jesús ya no llama a Dios $A b b a$, sino que se dirige a él. lastimeramente, como "Dios" (Mc 15. 33; Mt 27, 45). Según Lucas, Jesús sigue llamándole Abba (Lc 23, 46). Véase Jesucristo liberador, pp. 395-399. 
Esa es la pregunta fundamental para la evangelización, porque es la condición de posibilidad de su existencia, y eso es lo que hoy está en crisis. Desde esta perspectiva, la evangelización, en el sentido estricto del término, era más fácil en la década de los setenta y ochenta, dada la cercanía del Vaticano Il y Medellín en la Iglesia, y de los movimientos de liberación, populares, estudiantiles, revolucionarios en la sociedad. Ahora -y éste es elemento importante del nuevo paradigma-, esia convicción esperanzada se desvanece de diversas formas.

Y es que "buena noticia" en lo fundamental es el anuncio de que la verdad, la justicia, la dignidad, la fratemidad, la utopía de la vida en suma, son posibles en un mundo de marginación, inhumanidad y muerte. Dicho antropológicamente, es el anuncio de que en un mundo egoista, mentiroso y cruel es posible lo humano, veraz, honrado, misericordioso, jusio, esperanzado. Dicho jesuánicamente, buena noticia es el anuncio del fin de las desventuras para miles de millones de seres humanos, que viven hoy como deshechos y piltrafas en un mundo cruel. Dicho teologalmente, buena noticia es el anuncio de que Dios defiende y ama a los pobres de este mundo. Si así son las cosas, tiene razón Gustavo Gutiérrez cuando afirma que "la tarea más importante de la teología es cóno decir a los pobres que Dios les ama". Pero entonces vuelve a surgir la pregunta: ¿hay convicción de que la buena noticia es posible? Veámoslo.

\subsection{EI problema eclesial: miedo al evangelio y falta de credibilidad}

Ya en 1974 señalaba Schillebeeckx que las iglesias se vaciaban porque "estamos perdiendo la capacidad de presentar el evangelio a los hombres de hoy con una fidelidad creativa, junto con sus aspectos críticos, como una buena noticia"4. Veamos, pues, el problema eclesial.

a) Una Iglesia sin talante de evangelio. La Iglesia siempre tienc como problema fundamental el pecado que la acompaña. Pero por lo que loca a la evangelización puede ocurrir algo más grave, y es que la Iglesia actúe de tal manera que sofoque, tergiverse o simplemente anule el talante de eu-aggelion. Eso ocurre, en directo, cuando la Iglesia no comunica gozo, sino tristeza, sobre todo si ésta proviene de perder apoyos y privilcgios, como si en ellos estuviesc el motivo de su gozo. E, indirectamente, ocurre también cuando comunica prepotencia y arrogancia, como si para hacer presente la bondad de Dios lo más indicado fuese someter a otros con poder; o cuando maltrata al pueblo de Dios, por miedo a perder control jerárquico. Entonces, la Iglesia pierde credibilidad para comunicar algo que, por definición, debe ser recibido como "bueno". Y

4. Jesús la historia de un viviente, Madrid, 1981, p.103. El original fue publicado en 1974. 
finalmente, dicho lapidariamente, la lglesia deja de ofrecer una convicción de buena noticia, cuando muestra miedo al evangelio, a los mejores de su hijos e hijas, a sus propios santos y mártires.

Una Iglesia así no cumple éticamente con lo que ella misma predica, pero, peor aún por lo que aquí nos interesa, se dificulta y hasta se descualifica a sí misma para anunciar una buena noticia. $Y$ es que un ambiente de sospecha, de recelo y de autocensura, no comunican el gozo de la fraternidad, sino tristreza y miedo de perder lo poseído. La nostalgia de cristiandad, de cstar a buenas con otros poderes de este mundo, el horror a perder supremacía en el concierto de las religiones, no comunican cl gozo del servicio, sino la obsesión de ser servida. Suavizar o ignorar el "hecho de Jesús", su defensa del pobre y su enfrentamiento con los poderosos, su confianza en el Padre y su disponibilidad a dejarlo ser Dios, todo ello lleva a opacar al Jesús, que es en sf mismo euaggelion. $\mathrm{Y}$ es que la lalta de honestidad, de voluntad de verdad, no sólo son limitaciones éticas, sino que merman el gozo, pues "la caridad se goza en la verdad" (ICor 13,6).

b) La persecución y cooptación de una lglesia "evangélica". Según lo que acabamos de decir, la evangelización tiene dilicultades instrínsecas eclesiales, que son las más decisivas, pero también existen otras dificultades extrínsecas: el misterio de iniquidad reacciona contra una Iglesia -y contra cualquicr grupo humano- que quiera ser evangelizadora. Es escandaloso, pero es verdad: el mundo opresor no tolera que se anuncie una buena noticia a los pobres y opriinidos, y lo suele impedir de dos formas.

La primera, la más burda y la de siempre, comienza con Jesús ( $y$ antes que él, con todos los profetas): a quien anuncia una buena noticia a los pobres le va mal porque, para ser evangelizador, hay que ser simultánemente profeta, denunciador del mundo opresor. La evangelización como anuncio de la buena noticia a los pobres conlleva la persecución y hasta el martirio, y muy pocas iglesias están dispuestas a soportarlos, por lo cual se suelen reducir a comunicar lo doctrinal, pero sin dar el paso decisivo a anunciar lo evangélico. No hay que insistir mucho en esto, pues la historia reciente lo muestra con toda claridad. Afortunadamente, hay iglesias consecuentemente evangelizadoras y, por cllo, también inartiriales. Pero a la inversa, hay iglesias que no tienen nada de martirial, ni siquiera en un grado mínimo para poder ser análogamente mártires, y la razón. por paradójico que parezca, es que no han sido evangelizadoras, sino que se han reducido a la doctrina, las calequesis, los cánones...

La segunda, más sutil y actual, es la cooptación de la buena nolicia por parte de los poderes de este mundo. Así, teóricos del Fondo Monetario Internacional hablan del mercado como mediación e instrumento del reino de Dios. Y M. Novak, teólogo del capitalismo, dice que la expresión aclual del sicrvo sufricnte de Yahvéh, es la bussiness corporation. No nos resistimos a transcribir la cita entera. 
Durante muchos años uno de mis textos preferidos de la Escritura fue Isaías 53, 2-3: "Creció en su presencia como brote, como raíz en el páramo; no tenía presencia ni belleza que atrajera nuestras miradas ni aspecto que nos cautivara. Despreciado, evitado de la gente, un hombre hecho a sufrir, curtido en el dolor, al verlo se tapaban la cara; despreciado, lo tuvimos por nada". Quisiera aplicar estas palabras a la bussiness corporation modema, una encarnación de la presencia de Dios en este mundo extremadamente despreciada5.

La conclusión es clara. No es fácil manenter el talante de buena noticia en la Iglesia, o por falta de convicción de que así es Dios, o porque la convicción queda sofocada - como la semilla que cayó en el camino- por cl miedo y la prepotencia, o por la reacción del pecado del mundo contra una Iglesia que anuncia una buena noticia a los pobres y a las víctimas.

\subsection{El problema teologal: el poder de la injusticia}

El mundo actual tampoco facilita el talante y el anuncio de la buena noticia, por decirlo suavemente. En la humanidad de hoy no es que "lodavía-no ha llegado el reino de Dios", como nos enseñaba Cullmann, sino que "ciertamenteno ha llegado", ni está en vías de llegar, si nos alenemos a la realidad y no al discurso del sistema. La especie humana va a peor, pues ha llegado a surgir la subespecic de los no-existentes, y la familia humana va a mucho peor, pues el abismo entre seres humanos ricos y seres, igualmente humanos, pobres va en aumento. Epulón y Lázaro se distancian todavía mas. Se dice que estamos pasando de "lo injusto a lo inhumano"6, y lo que es peor, las soluciones que se proponen son malas, pues sólo podrían mejorar la vida de una determinada parte del planela (el 40 o el 50 por ciento), con lo cual alguna instancia tendrá que tomar la cruel decisión de decidir qué pueblos vivirán y cuáles no.

5. M. Novak y J. W. Cooper (eds.). The Corporation: A theological inquiry, WashingIon, 1981, p. 203.

6. Esto lo dice James Gustave Speth, administrador del Programa de Naciones Unidas para el Desarrollo. En su último informe, hecho público el 17 de julio, se dice que, en términos relativos. el abismo entre pueblos ricos y pobres va en aumento, y eso que en 1990 la relación era de 60 a 1 y de 180 a I si se comparan los más ricos y los más pobres. El patrimonio de las 358 personas, cuyos activos tienen un valor superior a 1,000 millones de dólares, supera el ingreso anual del 45 por ciento de la población mundial. Y en términos absolutos, la pobreza es denigrante para 3,000 milones de seres humanos; 89 países están peor que hace dicz años, y algunos de ellos peor que hace ireinta. Países como Costa de Marfil pueden tardar 6.5 años en llegar a los niveles de índice de desarrollo humano de los países industrializados. pero otros, como Mozambique y Niger. tardarán más de dos siglos. 
A esto hay que añadir la deshumanización programada por la "omnidinerización", la conversión en dinero de prácticamente todo (música, deporte, moda, diversión, turismo, religión electrónica), la trivialización de la existencia (consumismo), la individualización y el aislamiento real de personas y pueblos -a pesar de la globalización- que lleva a ignorar, desentenderse de y despreciar a los otros. Parafraseando el manifiesto comunista, dice Metz: "Un nuevo fantasma recorre Europa... Se está difundiendo una posmodernidad cotidiana de los corazones que arrumba la pobreza y la miseria del llamado tercer mundo en una mayor lejanía sin semblanle"7. Y si a la modernidad lc era constitutiva la expectativa de salvación —el advenimiento del reino de la libertad, de la sociedad sin clases-, la postmodernidad está limitando, si no anulando, la expectativa misma. La conclusión, por lo que loca a la evangelización, cs que la configuración económica mundial impone, por necesidad, la resignación; y para quienes tenían esperanza, el desencanto. En la acertada expresión de X. Gorostiaga, para que el actual proyecto económico mundial tenga éxito se impone "la geocultura Je la desesperanza y la teología de la inevitabilidad" 8 .

Todo esto genera un ambiente -que no cultura, pues no produce frutos, como to hace la agriculnura- de l'rivolidad, pero sobre todo de desencanto y desesperanza. Y entonces, no sólo la realidad de nuestro mundo no es en sí inisma una buena noticia, sino que parece suprimir toda posibilidad de que la haya: la buena noticia no es posible. Y lo que hay que recalcar es que ahora hablamos no ya de la dificultad eclesial, como en el apartado anterior, sino de la dificultad teologal. Lo que llamamos mundo no es sino la creación de Dios, la obra de sus manos, lo que él quierc guiar y atraer hacia sí. Esa creación a lo largo de la historia, y ciertamente en la actualidad, está como aplastada por el pecado. El poder de ese pecado, que tritura a seres humanos y deshumaniza a víctimas y verdugos, es la dificultad máxima para la convicción de que una buena nolicia es posible.

Scgún todo lo que acabamos de decir, el problema [undamental de la evangelización cstá, pues, en la convicción de su misma posibilidad, ante lo cual otros problemas son menores. Y para añadir seriedad al problema, recordemos que en esto se juega el ser o no ser de la lglesia, pues evangelizar no es una cosa más en ella, sino que "constiluye (su) identidad más profunda" (n. 14), de modo que todo en la Iglesia, incluida la oración, la escucha de la palabra, la caridad fraterna, cl pan compartido, "no tiene pleno sentido más que cuando se conviertc en lestimonio, provoca la admiración y la conversión y se hace predicación y

7. "Teología europea y tcología de la libcración", en J. Comblin. J. l. González Faus. J. Sobrino (eds.). Cambio sucial y pensamiemo cristiano en América Latina, Madrid. 1993. p. 268.

8. "La mediación de las ciencias sociales y los cambios internacionales". en ibid. p. 131. 
anuncio de la Buena Nucva" (n. 15).

Según esto, el problema eclesial fundamental no es la supervivencia de la Iglesia, sino su posible degeneración en organización puramente doctrinal, ideológica e institucional. El problema fundamental de la fe no es el posible ateísmo, sino el desencanto con respecto al evangelio. El problema teologal fundamental no es si hay convicción de que "hay Dios", sino de que "es bueno que haya Dios".

A continuación vamos a analizar, historizándolos, tres elementos esenciales en el proceso de evangelización, según el esquema de la Evangelii Nuntiandi: (1) qué es lo que hay que anunciar: la buena noticia de Jesús; (2) qué es lo que hay que hacer al servicio de ese anuncio: la praxis de liberación, y (3) qué testimonio hay que dar para hacer creible la cvangelización: lo humano sin añadidos, pero con concreciones.

Al final volveremos sobre la convicción de la buena noticia como condición de posibilidad de la evangelizacón, pero digamos ya desde ahora que la misma evangelización in actu, llevada a cabo adecuadamente, puede generar, mantener y hacer crecer la convicción. La realidad es dialécrica y la realización de la evangelización puede llevar a la convicción de que la buena noticia es posible.

\section{Anunciar a Jesús de Nazaret: sacramento y camino a Dios}

Segunda proposición. Evangelizar es anunciar a Jesús de Nazaret como la aparición de lo humano que, de esa forma, remite al misterio de Dios.

El primer elemento de la evangelización según la Evangelii Nuntiandi es el anuncio de la realidad de Dios y su Cristo, contenido transcendente de la fe, que nos ha sido dado como don y gracia por iniciativa de lo alto. Sin ese anuncio no hay evangelización cristiana, y ésta consiste, dicho concentradamente, en "proclamar el amor de Dios a los hombres manifestado en Jesucristo" (n. 26). Esto es eu-aggelion. Veámoslo.

Es sabido que en el Nuevo Testamento el término ell-aggelion admite sustancialmente dos acepciones. Buena noticia es lo que anuncia Jesús, el reino de Dios (lo que llamamos la mediación), y buena noticia es el mismo Jesús (lo que llamamos el mediador), sobre todo su destino salvífico de cruz y resurrección. Lo primero aparece más claramente en los sinópticos - y sobre ello volveremos en la tercera proposición,- y lo segundo aparece más claramente en Pablo, siendo Marcos quien mejor unifica ambos significados: buena noticia es lo que trae Jesús y lo que se proclama de Jesús crucificado y resucitado.

Pues bien, a estas dos acepciones neotestamentarias de eu-aggelior queremos añadir una tercera en la que nos queremos concentrar, la cual, aunque 
basada en el Nuevo Testamento, no está suficientemente recogida en las anteriores: buena nolicia es el modo de ser de Jesús, en su anuncio y servicio al reino de Dios, lo cual, estrictamente hablando, va más allá de su mensaje y su praxis 9 . Para iluminar la evangelización actual nos vamos a concentrar en ese modo de ser como buena noticia porque creemos que, sobre todo en nuestro mundo, es también la mejor mystagogía para captar la buena noticia, Iranscendente, de Dios y su Cristo.

\subsection{Jesús como buena noticla según los evangelios}

De la persona de Jesús, muerto y resucitado, el Nuevo Testamento dice que Irae salvación, que fue "entregado por nuestros pecados y resucitado para nuestra justificación”, lo cual es una buen nolicia. Esto, sin embargo, con ser fundamental, es derivado. Presupone una realidad que ya ha acaecido y que ha sido captada en una experiencia primaria: la vida y la muerte históricas de Jesús de Nazarel, más la experiencia escatólogica de la resurrección. La experiencia "más" primigenia, aunque abierta a ser completada, es pues la de la vida y cruz de Jesús de Nazaret, mientras que la experiencia del resucitado introduce en la verdad más plena de Jesús, pero queda siempre remitida a su historia. Por lo que toca a la buena noticia, esto quiere decir que todo se decide, en definitiva, en el impacto que causó aquel Jesús de Nazaret, impacto sacudido y trastocado por la cruz, y confirmado, creyentemente, por la resurrección. Ese impacto fue después teorizado, teologizado y relacionado con la salvación, pero lo fundamental se decide en si Jesús de Nazaret "hace una diferencia", en la terminología de Juan Luis Segundo.

Y es que no puede haber afirmación doxológica sin realidad histórica: no se puede decir "Jesucristo, el Señor, es salvador" sin alguna experiencia de la realidad histórica salvadora de Jesús (cosa que hay que aceptar a priori, si es verdad que Dios estuvo presente en Jesús de Nazaret). Eso es lo que en el inicio hizo la diferencia, y esto es lo que puso en marcha el proceso: de Jesús de Nazaret al Cristo - sin que se pueda revertir esa dirección. La pregunta, entonces, es qué hizo de Jesús una buena noticia, qué llamó la atención entre la gente pobre que "acudía a él de todas parles", la gente rural de Galilea, menospreciada por los movimientos religiosos 10 .

De Jesús atraía, sin duda, el mensaje de esperanza a los pobres, sus activida-

9. Eslo significa que a la ortodoxio y a la ortopraxis hay que añadir lo que, a falla de mejor expresión, pudiéramos Ilamar ortoparhos: el modo correcto de dejamos afectar por la realidad de Cristo.

10. Estas reflexiones pueden verse más ampliamente en “ ¿Es Jesús una buena noticia?”, Revista Latinoamericana de Teología 30 (1993), pp. 293-304. 
des liberadoras, curaciones, expulsiones de demonios, acogida a los marginados, su praxis de denuncia y desenmascaramiento de los poderosos. Pero atrala también su ralante, su modo de ser y hacer, que es lo que ahora queremos analizar. En Jesús veían a alguien que hablaba con autoridad, convencido de lo que decía, no como los que hablan como fanáticos irracionales o como funcionarios a sueldo. En sus Iribulaciones, la gente acudía a él, y al pedirle solución a sus problemas. lo hacía con lo que, al parecer, era siempre el argumento decisivo: "Scñor, len misericordia de nosotros". Los niños no se asustaban de él y también las mujercs lo seguían. Al final de su vida, en esa gente encuentra su mayor protección. Una mujer no pudo contener su entusiasmo y lo expresó con la mayor vivacidad: "Bendito el vientre que te llevo".

Los pobres, pues, los marginados, los débiles y sencillos, encontraron en Jesús a alguien que los amaba, los defendía y los liberaba. Sus seguidores, hombres y mujeres, quedaron impactados por su autenticidad, verdad, firmeza y, en definitiva, por su rectitud y su bondad. Esto, ayer como hoy, no es frecuente, impacta en la conciencia colectiva y es una buena noticia. Y es que incluso un salvador puede serlo de varias maneras: alejadamente y con poder, o ccrcanainente y con solidaridad. Parafraseando el tan citado texto de Miqueas 6 , 8, pudiéramos decir que Jesús fue buen mediador porque practicó la justicia y fue un mediador bueno porque amó con ternura.

En los relatos evangélicos hay, pues, un claro eco del impacto que causó la persona de Jesús, su modo de ser, y ese impacto histórico y personal es lo más decisivo para poder empezar a hablar de Jesús como buena noticia. Es cierto que el kerygma incluye y hace central el destino de Jesús como eu-aggelion: pero aquí, el eu-aggelion es ya una interpretación - positiva - del destino de Jesús, y por ello tiene un carácter derivado y doctrinal. En el contacto con Jesús, sin embargo, el eu-aggelion es realidad primaria. $Y$ hay que recordar que la fe no es la aceptación creyente de una interpretación de la realidad, sino que es el hecho de confrontarse con y abandonarse confiadamente a una realidad, que, entonces, puede ser creída e interpretada transcendentemente. La buena noticia de Jesús en el Nuevo Testamento no es, pues, sólo objeto de fe - la pascua trae salvación-, sino también realidad experimentada: la misericordia, la honradez, la firmeza de Jesús son cosas buenas, humanizan y dan esperanza a los pobres.

\subsection{Jesús como buena noticia en la actualidad}

Las reflexiones que acabamos de hacer son muy comprensibles desde nuestra actual expericncia salvadoreña. Si buscamos en Monseñor Romero las Ires acepciones de eu-aggelion que hemos analizado, se puede decir que (1) fue buena noticia su servicio a la realización del reino de Dios: el anuncio, la esperanza y la utopía que irradiaba, sus propuestas de solución para los conflic- 
los y para la reconsırucción del país; (2) su destino pascual, la solidaridad útima y el amor que expresó su muerie, la esperanza de resurreción en el pueblo salvadoreño y de que la liberación llegará a ser una realidad; (3) su modo de ser, cercano a las víctimas y profeta hacia los opresores; su compasión y bondad, su firmeza y honradcz. Todo ello humanizaba y atraía a los pobres y a toda persona de buena voluntad, y hacía de Monseñor Romero una buena noticia. Aun con independencia lógica de si su vida y su muerte tuvieron éxito, el ser así de Monscīor Romero ya lue salvílico, fue eu-aggelion.

Eso es lo que decimos de Jesús. Y si nos preguntamos qué es lo que hoy hace de él una buena nolicia. quizás podemos decir lo siguiente, recogiendo y sistematizando lo que aparece en los evangelios. De Jesús impacta la miscricordia y la primariedad que le otorga: nada hay más acá ni más allá de ella, y desde ella deline la verdad Je Dios y del ser humano; su honradez con lo real y su voluntad de verdad. su juicio sobre la situación de las mayorías oprimidas y de las minorías opresoras: voz de los sin voz y voz contra los que lienen demasiada voz, y su reacción hacia esa rcalidad: defensa de los débiles y denuncia y desenmascaramiento de los opresores; su fidelidad pura mantener a lo largo de la historia honradez y justicia hasta el final en contra de crisis internas y de persecuciones externas; su libertad para bendecir y maldecir, para acudir a la sinagoga en sábado y para violarlo, libertad, en delinitiva, para que nada sea obstŕculo para hacer el bien. De Jesús inpacta que quiere el fin de las desventuras de los pobres y la lelicidad y el gozo de sus seguidores, y de ahí sus bienaventuranzas; que acoja a pecadores y inarginados, que se siente a la mesa y celebre con ellos, y que se alegre de que Dios se revela a ellos. Finalmente, de Jesús impacta — para un creyenteque confía en un Dios bueno y cercano, a quien llama Padre, y que, a la vez, está disponible ante cse Padre que sigue siendo Dios, misterio absoluto e inmanipulable.

Ver hecha realidad en una persona cada una de estas cosas, honradez y verdad, misericordia y fidelidad, libertad, gozo y celebración, confianza en el Padrc y disponiblidad ante Dios, es siempre una buena noticia en nuestra historia. Pero impacta también, y quizás incluso más que lo anterior, el que en una misma persona aparezcan unidas y se reconcilien cosas difícilmente reconciliables en la historia. Jesús es, a la vez, hombre de misericordia ("misereor super turbas") y de denuncia prolética ("ay de ustedes los ricos"), hombre de recicdumbre ("quicn quiera venir en pos de mí, tome su cruz y sígame") y de delicadeza ("tu fe le ha salvado"), hombre de conlianza en Dios ("abba, Padre") y de soledad ante Dios ("Dios mío, z.por qué me has abandonado?").

Y así pudiéramos seguir. Lo importante es que - sea cual fuere la fortuna de la clescripción anterior- los evangelios nos presentan a un Jesús encarnando todo lo que es más humano y simultaneando todo lo que sea humano, y eso sigue atrayendo hasta el día de hoy. A ese Cristo que es Jesús le es esencial, pucs - tan esencial como su ser humano y divino, y su ser salvador-, ser buena noticia, que, por ser noticia, tiene que hacerse notar, y por ser noticia buenc tiene que aparccer como hueno para los seres humanos. 


\subsection{Jesús, sacramento de la buena noticia de Dios}

A lo dicho pudiera objetarse que, aun siendo verdad, manticne el anuncio de la buena noticia a un nivel meramente histórico - y es cierto que así lo hemos enfocado. Pero a csto hay que añadir que ese Jesús, el histórico, es también la mystagogía y el camino hacia el Cristoll, y es el sacramento de Dios en la historia. Y sobre este último punto queremos decir una palabra para que la evangelización abarque en principio la totalidad de su dimensión transcendente.

Lo que hemos dicho narrativamente de Jesús a propósito de los relatos evangélicos aparece en la teología del prólogo de Juan y en el de su primera carta en forma más leologal, pues Jesús aparece en ellas como el devenir del mismo Dios. Por lo que toca a la evangelización, hay que recalcar que ambos textos no sólo afirman una verdad —que resulta ser buena noticia-, sino que comunican en directo una buena noticia, que es tenida limemente por verdad.

La importancia específica de estos textos para la evangelización es que ponen a Jesús en relación con Dios: la buena noticia que es Jesús muesira que Dios es buena noticia. En las palabras tan ciladas de Rahner, Dios ha rolo para siempre la simetría de ser posiblemente salvador y posiblemente condenador. Dios es salvador. Considerado como (una verdad que es) buena noticia, el prólogo de Juan dice que sobre esta tierra de linieblas ha aparecido luz, que sobre este mundo de muerte ha aparecido vida y que en esle mundo de provisionalidades -incluidos Moisés y Juan Bautista - ha aparecido lo definitivo. Visto desde nosotros, dice que en este mundo se puede ser hijos e hijas de Dios, todo ello como don y gracia que viene de lo alto, de un Dios que ha devenido carne.

Pero además, el prólogo especifica en qué consiste la buena noticia que nos ha Ilegado con la palabra. En el v.17 - de traducción difícil, no tanto en su literalidad, charis kai aletheia, cuanto en su significado real- se explicita el contenido de la buena noticia. Literalmente pueden traducirse ambos términos como "gracia y verdad", siendo ya ambos "palabras-símbolo" que en sí mismas expresan algo sumamente bueno. Otras traducciones, sin embargo, intentan especificar y detallar un poco más el contenido de estas dos palabras-símbolo a partir de sus equivalentes en el Antiguo Testamento. Así, la Biblia española iraduce "el amor y la lealtad", la Biblia latinoamericana "el amor y la fidelidad", P. Miranda "la compasión y bondad"12, J. I. González Faus (en una paráfrasis, como él admite) "la misericordia fiel, característica de la Divinidad"13.

11. Véase lo que escribimos en Jesucristo liberador pp. 102ss.

12. El ser y el mesias, Salamanca, 1973, p.144.

13. La humanidad nueva, Santander, 1984, p. 330. 
Lo que eslas diferentes traducciones intentan transmitir es en qué consiste para nosotros la buena noticia de que la Palabra se ha hecho carne. La plenitud que hemos recibido es el hesed, la compasión de Dios. Es, pues, una gracia con la connotación especlfica de la parcialidad y ternura de Dios hacia los pobres de este mundo. Y es fidelidad, la de Dios, la de la roca firme (emeth). La buena noticia es que Dios nos ama, por gracia, tal cual somos, humanos, débiles también, pequeños; y que ese amor de Dios incluye por esencia su compasión, su misericordia hacia nosotros. Es un amor consciente, condescendiente. Y es también buena noticia la irrevocabilidad de ese amor, la fidelidad de Dios a sí mismo con respecto a nosotros. Eso es lo que se ha hecho presente en Jesús. La revelación de Dios, no es, pues, sólo verdad, sino que es simultáneamente, y con prioridad lógica, comunicación de una buena noticia. Evangelizar es hablar de Dios así.

La evangelización comienza, pues, con el anuncio de que ha aparecido lo verdaderamente humano - milagro grande y anhelado-, que es también el camino para poder captar la manifestación de Dios. Esto no es una concesión al secularismo, sino fídelidad al camino de la revelación - de Jesús a Dios- y ofrecimiento de una mystagogía adecuada para nuestro mundo. $Y$ a este anuncio verbal hay que añadir a qué lleva la aparición de lo humano: a la construcción del reino de Dios, y cómo se hace hoy presente lo humano: en el testimonio. Eso es lo que vamos a analizar a continuación.

\section{Construir el reino de Dios: utopía y profecía}

Tercera proposición. Evangelizar es construir el reino de Dios, denunciando el antirreino; es, pues, utopía y profecía. Y esto debe hacerse hoy, además, propiciando una adecuada "ecología del espíritu".

En Jesús es claro que evangelizar no es sólo anunciar - actividad comunicativa verbal que genera esperanza-, sino construir el reino de Dios -actividad práxica, transformadora de la realidad. Este punto es también el más novedoso en la Evangelii Nuntiandi y en su día causó sensación: a la evangelizacion le compete no sólo anunciar la salvación, sino la liberación de millones de seres humanos, y no sólo le compete anunciarla, sino "ayudar a que nazca esta liberación, de dar testimonio de la misma, de hacer que sea total" (n. 30).

Eso es también lo que han recalcado la teología y la cristología de la liberación, y por ello no vamos a inistir en lo central de la tesis. Pero sí queremos hacer tres reflexiones alrededor de ella, pues la utopía del reino y la denuncia del antirreino están sufriendo hoy la muerte de mil cualificaciones. 


\subsection{La utopía de la liberación: dálectica de lo grande y lo pequeño}

a) Lo específico de la evangelización como liberación histórica. Que a la evangelización le compete la liberación fue el gran descubrimiento de Medellín, entonces asumido por muchos. Sin embargo, el confliclo y la persecución que originó, y el hecho de que no llegaron las liberaciones esperadas, ha hecho que la liberación no sea ya concebida como tarea central (a veces ni siquiera periférica) en la misión de la Iglesia, y que se la cuestione incluso en grupos que antes fueron de avanzada. Esta conclusión, aunque comprensible, no es lógica, pucs la liberación sigue siendo exigida por el evangelio y por la tragedia de nuestro mundo. Lo que sí hay que hacer es precisar el aporte que la Iglesia puede y debe hacer a la liberación.

El primer aporte, específico y fundamental, es conocido, pero debe ser recalcado. En palabras de Mons. Romero, "la Iglesia no predica ningún sistema concreto. La Iglesia no ofrece ningún método, pero la Iglesia ofrece los principios de la verdadera libertad: creer en el Dios liberador"14. Esto puede parecer un mínimo, pero es un máximo si se toma en serio, pues signfica elevar la liberación a realidad teologal y, por ello, a realidad última. Y la contraprueba está en que hoy, simultáneamente, va desapareciendo el lenguaje sobre un Dios liberador y el lenguaje sobre la liberación. Pero, a la inversa, si mantiene la confesión de un Dios liberador, la Iglesia se orienta toda ella —y orienta a la sociedad- desde y hacia la utopía de la justicia y la humanización, y a partir de ahí podrá historizar todos sus estamentos y realidades internas.

Esto es lo que hizo la teología de la liberación al elaborar el concepto de Iglesia de los pobres, y lo importante es que lo hizo en nombre de un Dios de los pobres. Lo mismo debe decirse de la correlación enıre Dios liberador y evangelización liberadora. Se trata, como en la teología, de que en la evangelización esté actuando el "principio liberación". Y desde ese aporte específico. guiado por la fe cristiana e imbuido de valores cristianos, la Iglesia debe dar un segundo paso: aninar y trabajar junto con otros para "crear modelos económicos, polf́ticos y culturales que hagan posible una civilización del trabajo como sustitutiva de una civilización del capital"15.

Hoy es importante mantener la necesidad de ambos aporlcs, pues pareciera que dada la dificultad de transformar el mundo, la Iglesia ya nada tiene que decir y hacer al nivel de la liberación y cae en la grave tentación de desentenderse de clla. Lo que se necesita es una visión adecuada de lo que puede y debe aportar la fe cristiana a la liberación y lo que no puede ni debe, tal como lo

14. Mons. Romero, "Homilía: del 9 de julio de 1978, en Monseñor Oscar A. Romero. Su pensamiento V, San Salvador, 1980-1988, p. 58.

15. I. Ellacurfa. "El desaffo de las mayorias populares", ECA 493-494 (1989), p. 1078. 


\section{decía Ignacio Ellacuría:}

Carece de sentido objetar que la enseñanza social de la Iglesia o la teología de la liberación no ofrecen soluciones plenamente operativas a los problemas de la humanidad. De esa carencia no se sigue que su aporte histórico sea inútil o pueda ser sustituido por el de otros. La liberación integral no se puede lograr sólo con los instrumentos que ofrece la fe, pero no puede lograrse sin ellos. La integridad de la liberación exige esa presencia de la fe16.

El aporte específico a la liberación es, entonces, una determinada fe: la fe en un Dios liberador, la cual guiará, corregirá y animará a praxis concretas de liberación.

b) La tensión entre lo grande y lo pequeño. La inmensa dificultad de la liberación, de "revertir la hisloria", ha llevado a privilegiar ahora una evangelización que, en cuanto praxis transformadora, se concentra en lo pequeño y tiende a abandonar la totalidad. Esta praxis es necesaria y trae muchos bienes, porque acerca a la Iglesia a la realidad concreta y porque lo pequeño puede ser concebido como un universal concreto, que no tiene porque cerrar, sino que puede abrir a la totalidad, como en la pastoral de Rutlio Grande, por ejemplo. Pero liene también sus peligros, si se la eleva a criterio último y único de acción, pues de esta forma se puede falsear el horizonte de la misión, que, en definitiva, no es otro que la voluntad de Dios para su creación. Si la vuelia a lo pequeño que estamos experimentando en nuestro tiempo se presenta como alternativa, teórica y prácticamente excluyente, a una liberación efectiva y abarcadora, la Iglesia, sutilmente y aun con buena voluntad, estará desentendiéndose de su responsabilidad hacia el mundo como tal, pues el mundo es una realidad estructural y totalizante, y necesita soluciones también estructurales y totalizantes.

Cierto es que las actividades de Jesús, las curaciones, las expulsiones de demonios, la acogida a los marginados, eran signos y sólo signos del reino, pero hay que recordar que eran signos que lo expresaban, que ponian en la dirección de lo que debía ser la totalidad, y que, en cuanto signos liberadores, expresaban el triunfo sobre las raices de la opresión, y en ese sentido comunicaban la esperanza de que la liberación como tal, no sólo algunas mejoras benéficas, era posible. Además, su profecía tocaba, evidentemente, las estructuras religioso-políticas, económicas, culturales, de la sociedad. Y su destino lo muestra con toda claridad.

No hay por qué oponer, pues, signos a reino, lo pequeño concreto a la totalidad estructural, pero hay que relacionarlos adecuadamente, es decir, dialécticamente:

16. I. Ellacuría, "Liberación”, en Casiano Florislán y Juan José Tamayo (eds.), Conceptos fundamentales del cristianismo, Madrid, 1993, p. 704. 
que lo pequeño concreto lleve a captar la profundidad de la realidad y a la absoluta necesidad de re-accionar con misericordia, es decir, que lleve a lo totalidad, cuantitativa y cualitativamente; y que la totalidad estructural lleve a poner signos y a dar pasos concrelos, para expresar caminos de solución. Esta dialéctica —comunidades de base y movimientos de liberación, pastoral popular y teología de la liberación, por ejemplo- estuvo muy presente en décadas pasadas, pero tiende hoy a romperse, como hemos dicho. Por ello nos parece necesario recalcar la dimensión de totalidad e integrar en esa visión las acciones concretas evangelizadoras 1 ?.

Los pasos hacia la utopía pueden ser modestos, pero lo importante es el pathos del caminar y la mística del horizonte. El horizonte de la evangelización no es cualquier cosa, sino la creación de Dios, lan necesitada de salvación. Esta era la mística de toda una generacion eclesial anterior, y así l. Ellacuría, cuando definió a Monseñor Romero, lo hizo en estos términos: "un enviado de Dios para salvar a su pueblo". Al pueblo hay que salvarlo con muchos y variados aportes, pero lo importante es mantener o recobrar el horizonte: se trata de la salvación de un pueblo, de la salvación de la creación de Dios.

\subsection{Profecía: la denuncla del antirreino}

En los evangelios, el reino de Dios es una realidad dialéctica a la que se le opone activamente el antirreino. Sería ingenuo e irreal, pues, anunciar e intentar construir el reino sin denunciar e intentar destruir el antirreino. Esto, sin embargo, de gran raigambre biblica y latinoamericana - ya en el siglo XVI y en las últimas décadas-, tiende ahora a ser ignorado, como si la realidad del mundo actual lo hiciera innecesario, cuando la verdad es exactamente la contraria. La caída del bloque socialista, además, ha supuesto la pérdida de un contrapeso eficaz de modo que los poderosos de hoy pueden hacer caso omiso de denuncias menores. "Ofrecemos una buena solución, nos dicen. Y es la mejor porque es la única". Pero el problema subsiste: el anlirreino está activo y hace contra el reino. Por ello, en la Iglesia la denuncia es necesaria ética, antropológica y socialmente, y, si se nos entiende la expresión, hasta metafísicamente.

Lo es éticamente para no violar, por encubrimiento, el oclavo mandamiento - y al menos en el cumplimiento de los mandamientos de la ley de Dios la

17. La actual situación en Zaire, Ruanda y Burundi ilusıra bien lo que queremos decir. Es evidente la urgencia e importancia de ayuda humanitaria a los refugiados y víctimas, y es conmovedor el testimonio de muchas personas. Pero son estas mismas personas, las más entregadas y las más dedicadas a "lo concreto", por asi decirlo, las que claman por planteamientos y solucioncs "estructurales, políticas y económicas". No hay oposición, pues, sino complementación. Por ello, la lglesia, en cuanto pueda, en tareas concientizadoras y educativas, en su teologia del conflicto y de la utopia, debe mantencr la dimensión de tolalidad del problema y de la solución. 
Iglesia debiera dar ejemplo.

Lo es antropológica y socialmente para edificar la persona y la sociedad sobre la verdad. Con la denuncia evitamos que se cumpla la amenaza de Isaías, "ay de los que llaman día a la noche y noche al día", y la de Pablo contra "los que aprisionan la verdad": contra ellos se revela la cólera de Dios, su corazón se entenebrece, las cosas ya no manifiestan lo que son y quedan entregados a todo tipo de deshumanización. Sobre la verdad de la realidad se puede edificar, como sobre roca firme, el edificio humano y social; sin ella, larde o temprano se desmorona. Es cierto, como hoy se dice, que "no hay prolesta sin propuesta", pero esto no quita nada a la necesidad de la denuncia, pues ésla no es, formalmente, protesta, desahogo subjetivo, sino que es dar cuenta de la verdad de la realidad.

Y lo es metafisicamente, porque la denuncia pone de manifiesto la dimensión dialéctica y duélica de la realidad - dimensiones ambas muy tenidas en cuenta hace unos años, pero más ignoradas ahora, también en la Iglesia. El que Dios se revela a favor de unos y en contra de olros, el que hay Dios e ídolos, el que hay mediadores, unos como Jesús y otros como los sumos sacerdoles, el que hay utopía del reino de Dios y realidades de antirreino -en pugna unas contra olras - es central para comprender la revelación y la historia. El no verlo así puede ser ingenuidad, pero en realidad es ignorancia interesada para no admitir que el mundo no es el que todavía-no ha llegado a ser lo que debiera por "falta de liempo", sino por las fuerzas maléficas que hacen contra la utopía y generan víclimas. La denuncia nos remite, pues, a la verdad, sobre ella se puede edificar, y eso es buena noticia.

Además, la denuncia, con mayor claridad en esto que el anuncio, apunla a la dimensión estructural de la realidad. Dicho en palabras sencillas, si es difícil saber lo que es justicia esinuctural y cómo promoverla, es fácil saber lo que es la injusticia estructural y que hay que combatirla. La denuncia ayuda, pues, a recordar que los males plurales provienen de un mal mayor, estructural, producto de poderes religiosos y, sobre todo, de poderes culturales, económicos y políticos. Y por trágico que parezca es un bien recordarlo y no responsabilizar del mal sólo al corazón del ser humano.

Por último, además de necesaria, la denuncia produce esperanza. La verdad no sólo no existe, sino que es encubierta y está oprimida, y de ahí que la denuncia consista no sólo en poner en palabra la verdad de la realidad, sino que es liberación de la verdad. Y esa liberación, como toda liberación, produce esperanza: es posible liberarse de la mentira, se ha hecho posible lo que parecía imposible, el mal puede ser vencido.

No vivimos hoy en un mundo y en una Iglesia profélica, donde se denuncia lo que se debe. A quien hoy denuncia se le suele llamar negativo, resentido, 
poco realista, anacrónico. Muchas de las denuncias eclesiales, por ejemplo las de Juan Pablo II, en materia social, suelen ser ignoradas o efjcazmente cooptadas por el sistema. $Y$, paradójica e incomprensiblemente, dentro de la misma Iglesia no suelen encontrar, en general, apoyo decidido y creativo en la nueva generación de obispos nombrados en este pontificado. Por ello, mantener la denuncia es una buena noticia para defender a los pobres de una realidad que es opresora, y que cada vez lo es más impunemente.

Jesús, el evangelizador, fue lambién, simultánemante, el profeta y denunciador. La prioridad, lógica y cronológica, está en la evangelización, pero precisamente por ser evangelizador, defensor del pobre y del débil, fue denunciador de estructuras y grupos sociales. Desde Jesús es muy claro que la denuncia es buena noticia para el débil porque lo defiende de su opresor, pero terminemos diciendo que también lo es para el opresor sub specie contrarii, porque lo puede mover a conversión 18 .

\section{La ecología del espíritu}

Nuestro mundo no sólo está oprimido en su cuerpo, sino también en su espíritu. Por ello l. Ellacuría proponía una nueva civilizacion que él llamó consciente y provocalivamente "civilización de la pobreza". Lo hizo así para recalcar que hay que superar la actual "civilización de la abundancia", propuesta por los poderes de este mundo como la civilización oficial y que debe ser superada dialécticamente desde su contrario. Esta civilización oficial, en efecto, no ha resuelto el problema de la pobreza, pero tampoco el de la humanización. No ha civilizado ni a los que viven en la abundancia ni a los que viven en la miseria. De ahí que la evangelización deba transformar también la civilización, los valores o los pseudo-valores que configuran lo humano en el mundo actual. Por decirlo en lenguaje gráfico, abogamos porque la evangelización propicie una adecuada "ecología del espíritu".

Usamos esta metáfora porque la ecología está de moda, en el mejor sentido de la palabra, y porque el problema ecológico es de vida o muerte. No es, pues, un problema más, sino aquel que hay que resolver para que la vida sea posible. Lo ecológico es, además, omniabarcador y estructural, todo y todos estamos implicados en ello, sepámoslo o no; no es, pues, sólo un problema regional. Por último, la actual situación ecológica es producto de males históricos; no es pues que la tierra está mal, sino que está maleada.

18. La Evangelii Nuntiandi, tan inportante por otros capitulos, no menciona la denuncia como parte de la evangelización. Sólo menciona, de pasada, que a la evangelización le compete también "la predicación del misterio del mal" (n. 30), frase que aparece, por cierto, al analizar la realidad del tercer mundo (nn. 30-38). 
Pues bien, uno de las urgencias ecológicas - y aquí viene la explicación de la metáfora en nuestro contexto- es la purificación del aire que respiramos, símbolo primario de vida. Y así como el cuerpo necesita de aire puro, así también lo necesila el espíritu. Liberar hoy es, pues, purificar el ambiente, la mal llamada civilización actual. En este sentido, hablamos de la necesidad de evangelizar el ambiente, de propiciar una adecuada ecología del espíritu.

Con esto no estamos proponiendo una "cultura cristiana", en el sentido en que lo hacen los nostálgicos de la cristiandad: que las creencias y normas éticas eclesiásticas impregnen la vida social y que así la Iglesia pueda subsistir con facilidad, controlar y medrar - aunque ello fuese para el bien de la humanidad. Nos referimos, más bien, a la humanización de la cultura y esto si se puede (y se debe) hacer desdc una perspectiva evangélica y cristiana. En qué consista esa humanización del espíritu es cosa a discernir, pero quizás ayude la siguiente fenomenologfa.

Para una adecuada ecologla del espíritu ante todo hay que recuperar la utopía en contra del desencanto, aunque esta utopía sea tan sencilla $-y$ tan positiva y sin lugar - como el que la vida sea posible. Hay que promover el espíritu de comunidad versus el individualismo aislacionista, que fácilmente degenera en egoísmo; la celebración versus la pura diversión irresponsable, industrializable y comercializable, que degenera en alienación; la apertura al otro versus el etnocentrismo cruel, que degenera en desentendimiento del sufrimiento de los otros, en su desprecio y opresión; la creatividad versus el mimetismo indolente y la imitación servil, que fácilmente degenera en pérdida de identidad propia; el compromiso versus la mera tolerancia, que degenera en indiferencia; el espíritu de justicia versus la pura beneficencia, con la que se encubre y se pretende paliar la tragedia del mundo; la solidaridad versus el independentismo de quien no necesita de nadie, aunque termina en soledad; el espíritu de verdad versus la propaganda y la mentira, de lo cual tarde o temprano se venga la realidad; la memoria y el recuerdo versus el olvido, que degenera en impunidad para malhechores y en ingratitud hacia las víctimas; la fe versus el burdo positivismo y pragmatismo, que degeneran en sinsentido de la vida; la Iglesia de los pobres versus una Iglesia falsamente universal, de todos, que apoya al poderoso...

Sea cual fuere la fortuna de esta fenomenología, lo que con ella se quiere decir es claro: evangelizar es humanizar el aire que respira el espfritu. Y, cristianamente, es poner al ser humano, a través de esa humanización, en el camino de la jesuanización, de la deiformación, explícita o anónimamente. En este sentido, es verdad que el cristianismo "debe predicar religiosidad, enseñar a los hombres a plantearse seriamente el problema de la ultimidad de su existencia"19. No se

19. Loln Entralgo, Vida Nueva 2.050 (1996), p.11. 
trata de volver al proselitismo eclesial, sino de ofrecer una mystagogia de humanización.

Y añadamos que fomentar la ecología del espíritu es tarea específica de instituciones como la Iglcsia, y para la que está mejor preparada, por su naturaleza, que para otras. En efecto, estí luera del alcance de la Iglesia influir direcla e inmediatamente en la transformación económica, pues para ello no tiene los medios económicos, tecnológicos, políticos o militares adecuados, pero sí está a su alcance influir en la translormación del ambiente social. Para cllo cucnla con la palabra como realidad configuradora del espíritu humano, con tradiciones importantes (como ocurre con los mártires en El Salvador) y cuenta con una red de instituciones para difundirla: diócesis y parroquias, colegios y universidades, publicaciones y medios de comunicación. A través de todo ello puede introducir en la sociedad la palabra que configura al espiritu y contrarrestar otras palabras deshumanizadoras $-y$ el Vaticano puede potenciar todas las voces locales. (S6lo que hay que recordar que evangelizar el aire que respira el espíritu lleva lambién a la persecución y al martirio.)

Lo más importante de lo dicho en este apartado es, en delinitiva, que en la cvangelización hay que volver a la maternalidad como dimensión más original de la lglesia. La Iglesia es "madre y maestra". pero es antes madre que maestra, y ello no sólo por la connotación de misericordia que tiene el térınino "madre" -y que buena falta le hace-, sino por la connotación de "partera de humanidad", que no es exactamente lo mismo y tiene prioridad sobre el ser "experta en humanidad". Más que enunciar, evangelizar cs, en definitiva, dar a luz, parir el reino de Dios.

\section{Dar testimonio en la realización de lo humano}

El testimonio es esencial a la evangelización. Hacc presente una buena noticia y otorga credibilidad al anuncio. Evangeliza lo humano sin añadidos, aunque con concreciones. $Y$ se evangeliza caminando con Dios, en una historia cambiante, humildemente y con la esperanza de los pobres.

Nuestra última reflexión versa sobre el testimonio: cómo relacionar el contenido de la evangelización con la propia vida. Es lo que recalca la Evangelii Nuntiandi: "La Buena Nueva debe ser proclamada, en primer lugar, mediante el testimonio" (n. 21).

El testimonio cs esencial a la evangelización porque da credibilidad a lo que se anuncia y ello ayuda a que el oyente acepte buenas noticias que son diffciles de aceplar por escandalosas: "el reino de Dios es de los pobres". Además. el testimonio hace real ya, de alguna forma, el contenido de la buena noticia: es posible ser humano. Lo que queremos analizar ahora es en qué consiste el testimonio específicamente evangelizador. En lo fundamental consiste en rehacer actualizadamente lo que hizo Jesús y como to hizo Jesús, pero nos queremos 
concentrar en tres aspeclos del lestimonio por su importancia en la actualidad.

\subsection{Lo humano "sin añadidos", pero "con concreciones"}

Para determinar lo central del testimonio vamos a aplicar al evangelizador lo que la carta a los Hebreos dice del mediador: que es verdaderamente humano. Recordemos que la carta describe al mediador con tílulos excelsos, Señor, Cristo, Hijo de Dios, pero recalca sobre todo su realidad humana, y por ello usa repetidamente el nombre de Jesús, lo que hace especialmente en el contexto de la debilidad, flaqueza y muerte20. Esto no es pura obviedad, ni la finalidad al mencionar el nombre de Jesús es la de identificar fácticamente quién es el mediador. Su interés consciente es recalcar que Jesús es realmente humano y participa de la condición humana, que fue "probado en todo igual que nosorros, menos en el pecado" (4, 15), que, más aún, "fuvo que asemejarse en todo a sus hermanos" $(2,17)$.

Este Jesús humano no necesita de ningún añadido categorial para ser mediador, pertenecer, por ejemplo, a una delerminada tribu - la de Leví-, o recibir, como ocurre en el sacerdocio ministerial, una polestad añadida. La posibilidad de ser mediador no le viene, pues, de una realidad o determinación sociológica añadida a lo humano, ni le viene de una dignidad sobrehumana (como normalmente suele comprenderse el sacerdocio en las religiones). Ese no necesitar "añadidos" es el significado más profundo del recordalorio de la carta: "es cosa sabida que nuestro Señor nació de Judá, y de esa tribu nunca habló Moisés Iratando del sacerdocio" $(7,14)$. En este sentido, insistir hoy en que Jesús fue un "laico" tiene no sólo un valor polémico, sino que es otra forma de recalcar lo fundamental: "laico" o "sacerdote", por así decirlo, Jesús es mediador por ser humano y no por ninguna otra razón añadida.

Según esto, el evangelizador hoy tampoco necesita añadidos, pero, como Jesús, necesila "concreciones", "expresiones" concentradas de lo humano verdadero. De éstas, unas son naturales e inevitables, y otras son históricas, fruto de la libertad, y por ello evangelizadoras. En Jesús, lo humano se concretó, según la naturaleza, en un género, el de varón, y en una etnia, la judía, pero esto no significa que estas concreciones le sean esenciales a su capacidad mediadora. En Jesús, lo humano se hace presente en y a través de lo varonil y de lo judio, pero, estrictamente hablando, lo humano pudiera haberse hecho presente a través de lo femenino y de lo no judio.

Estas - u otras - concreciones naturales son evidentemente necesarias, pero

20. Cfr. Oriol Tuñi, “"Jesús' en la Carta a los Hebreos", en Revista Latinoamericana de Teologia 9 (1986), pp. 284-286. 
no son las que convierten en inediador a lo humano de Jesús. Esıo útiıno depende de otro tipo de concreciones: las que son libres e históricas. Hay diversas formas de ejercer lo humano y el verdadero mediador lo hace de una manera determinada -y lo mismo hay que decir del evangelizador. Veamos cuatro concreciones fundamentales de lo humano.

En primer lugar, lo humano como misericordia. La carta recalca la compasión de Jesús ante las flaquezas de los seres humanos: "no tenemos un sumo sacerdote que no puede compadecerse de nuestras flaquezas" $(4,15)$. Y en los sinópticos Jesús define al hombre cabal y al Padre celestial desde la misericordia, mientras que los evangelistas lo describen también a él desde ella: el reaccionar ante el sufrimiento de las víctimas por ninguna otra razón más que la existencia de dicho sufrimiento. Que esto le pertenece como algo esencial al evangelizador se desprende de cómo la carta compara, polémicamente, a Jesús con los sacerdotes del antiguo culto, según el criterio de la misericorida. Jesús vive en cercanía y compasión hacia los seres humanos, aquéllos en distanciamiento y rigor.

En segundo lugar, lo humano como fidelidad a Dios. La carta muestra a Jesús en su creaturidad y en lo que en ella hay de llaqueza, condición de posibilidad de la fidelidad teologal; y así, dice de Jesús --central y conscientementeque "debió asemejarse en todo a sus hermanos" $(2,17)$, incluida la tentación. que "fue probado en todo igual quc nosolros exceplo en el pecado" $(4,15)$. Y esa creaturidad queda expresada también a nivel teologal. Jesús se pone ante Dios con humildad, con "ruegos y súplicas, con poderoso clamor y lígrimas al que podía salvarle de la muerte" $(5,7)$-la siluación en el huerio-, y en oscuridad y no saber, "aun siendo Hijo" - lo cual hace escandaloso lo que sigue- "aprendió obediencia" (5, 8).

En tcrcer lugar, lo humamo como entrega. En la conceptualización de la carta, la mediación se ejerce, en definitiva, al ofrecer el sacrificio. Desde esta perspectiva lo que hace la carta es descualificar el sacrificio como "añadido" y exigir la entrega como "concreción histórica" de lo humano. Así, los ritos cultuales son descritos como "ritos carnales" $(9,10)$, y de cllos dice, sin más argumentación que lo que es evidente: "es imposible que sangre de toros y machos cabríos borre pecados" $(10,4)$. Esos sacrificios no son expresión de "lo humano", mientras que sí lo es la entrega de Jesús: los ritos son su misma vida y muerte. Se ha quebrado aquí la estructura de exterioridad lípica de la mediación cúltica -"los añadidos" en nuestro lenguaje- y se ha impuesto la estructura dc realidad y de la concreción hisiórica: la vida de Jesús es la expresión de la voluntad de Dios $(10,55 s)$ y la entrega de Jcsús es la que está llena del Espíritu $(9,14)$.

Por último, lo humano como solidaridad. La carla lo alirma descriptivamente al recordar la participación de Jesús en las naquezas y limitaciones de los 
demás. Y lo afirma programáticamnente en la bellísima expresión: "no se avergüenza de llamarles hermanos" $(2,11)$. Este término hermano, que desafortunadamente no ha generado una tradición cristológica equivalente a la de los títulos de dignidad, es fundamental. Con él se afirma que lo humano de Jesús se realiza al modo de solidaridad, $y$, consecuentemente, que todo lo humano verdadero tiene que ser solidario. Jesús, en definnitiva, puede ser mediador no sólo por tener una naturaleza humana, lo cual es sólo condición de posibilidad, sino por ser hermano. La condición necesaria y suficiente para ser mediador es ser humano al modo de fraternidad.

\subsection{El humilde caminar en la historia}

A lo dicho hay que añadir otra expresión de lo humano, necesaria siempre y más en momentos de oscuridad como el actual. Ser humano signilica caminar en la historia, y quizás la mayor tentación de hoy para la evangelización sea precisamente la de dejar de caminar, sobre todo dejar de caminar en la línea del concilio, de Medellín, de Monseñor Romero, aunque para ello se aduzcan (aparentemente) buenas razoncs. Y es también tentación el pretender rchufr el "humildernente", como si la Iglesia lo supiera todo - problema acuciante en el actual pontificado. Dada la novedad de la historia, no hay que anclarse en el pasado ni hay que intentar repetir mecánica y miméticamente sus mejores moinentos, pero sí hay que mantener "la dirección" del caminar que proviene de Jesús, de Medellín, de los mártires, y hay que mantener sobre todo "el caminar mismo", aunque sea en oscuridad, sin saber exactamente hacia dónde se va, "humildemente".

Si se toman las cosas con seriedad, el problema viene de lejos. La oscuridad -por cierto, más radical que la actual- comenzó con el mismo cristianismo. No lleg6 el reino de Dios anunciado por Jesús ni acaeció la parusía que esperaban los primeros cristianos. Desde entonces, al anuncio de la buena noticia y a la fe en el misterio de Dios le es esencial incorporar en ellas el momento de humildad, de no saber, de dejar a Dios ser Dios, de esperar una buena noticia aun en ticmpos de oscuridad y desolación. Y la lección importante para nosotros de aquellos primeros cristianos es que, a pesar de todo. rehicieron su fe y siguicron anunciando una buena noticia.

Ese re-hacer la buena noticia tuvo sus problemas, y en nuestra opinión, el más fundamental lue el de qué hacer con Jesús de Nazaret y con el reino de Dios, que fueron siendo sustituidos, paulatinamente, por un Cristo (excesivamente) transcendente y por una Iglesia (excesivamente institucionalizada y, después, encubridora del reino). Pero también en esto hay que mencionar la otra gran lección de los inicios: la vuelta a Jesús y al reino de Dios, que operan los sinópticos; en otras palabras. la fidelidad al origen fundante. 
Volviendo al testimonio, a éste le compete el mantenerse en el anuncio de la buena noticia a pesar de lodo. Esto significa caminar en la historia, pase lo que pase, seguir ofreciendo la convicción - no rutinariamente ni como gracia barala- de que la bondad es más honda que el mal. A la identidad del evangelizador le compele entonces ser humano, también y esencialmente, en esta dimensión del caminar.

Lo humano, por creatural, debe estar ante Dios, pero no puede estar en posesión de Dios. En fe creemos que venimos de un origen bueno, que, por gracia, ha generado este dinamismo que llamamos vida e historia. En esperanza esperamos que vamos hacia una plenitud, en la que, por gracia, será Dios todo en todos. Pero entre ambas convicciones transcendentes está lo histórico: el caminar. Y eso es también lo que ejemplificó Jesús y lo que afirma la Carta a los Hebreos. Desde esta perspectiva hay que recalcar que el cristianismo es una "religión del caminar". El cristianismo es experto en el caminar y desde ese caminar histórico, como Jesús, puede formular la transcendencia del origen y del final. Pero, obviamente, no "sabe" de igual forma sobre el caminar histórico que sobre la transcendencia. Lo específico cristiano es planlear la transcendencia desde el caminar y la humildad de lo cristiano consiste en que sólo puede hacerlo desde ahí.

Volviendo al caminar de Jesús, a su fidelidad creatural lc compete la procesualidad, el tener que caminar en la historia. De Jesús dice la carta, varias veces, que "llegó a la perfección", y no se le ahorró, por lo tanto, el tener que llegar a ser humano. Cristo es Hijo desde su origen y lo será para siempre, como también su sacerdocio mediador, pero ese "siempre" tiene una historia y en ella se ha expresado la fidelidad de Jesús. Fidelidad significa dejar a Dios ser Dios, y en forma lapidaria, dice la carta, con claridad que no tiene paralelo en el Nuevo Testamento, que Jesús se relacionó con el misterio de Dios en fe: Jesús es el que ha vivido originariamente y en plenitud la fe $(12,2)$, el que, en fe, ha caminado en la historia.

Con esto volvemos, una vez más, al texto de Miqueas. Si se nos permite una interpretación libre podemos decir que tenemos que evangelizar anunciando el reino de Dios y transformando esie mundo, es decir, practicando la justicia. Tenemos que evangelizar siendo nosotros mismos evangelio, es decir, amando con ternura. Tenemos que evangelizar como creaturas, es decir, caminando humildemente con Dios. Con todo ello podemos humanizar a nuestro mundo y hacer presente a Dios en él. En palabras de Monseñor Romero, podremos sentir "la alegría de sentirnos acompañados por Dios en la historia"21.

Quizás lo más importante que hoy puede hacer la Iglesia, en momentos de oscuridad para muchos, es seguir caminando, no pactar con lo que se nos impo-

21. "Homilia" del 9 de diciembre de 1979, VI, op. cit., p. 153. 
ne como inevitable, dar testimonio de que la buena noticia es posible, testimonio de seguir caminando en la historia porque "no podemos ser de otra manera".

\section{La esperanza de los pobres}

Queremos terminar estar reflexiones por donde comenzamos: de dónde sacar la convicción de que la buena noticia es posible. Ya hemos dicho al principio que una evangelización llevada a cabo tal como la hemos esbozado quizás pueda generar y hacer crecer la convicción de que es posible anunciar una buena noticia. En otras palabras, quien tenga la audacia de evangelizar así, aun en medio de oscuridades, quizás llegue a la convicción - y al gozo- de su posiblidad.

Pero hay otra vía de fomentar dicha convicción que es la de volver a los pobres. Y ello por dos razones que quisiera exponer muy brevemente. La primera es de orden teórico. Una noticia, en cuanto noticia, puede ser verdadera o falsa en su contenido, peto cuando decimos de ella que es buena o mala entonces, por definición, hay que tener esencialmentc en cuenta al destinatario, pues una misma noticia no es igualmente buena (o mala) para todos - y eso ocurre lambién en el crislianismo.

Esto no se ha tenido muy en cuenta y se ha dado por supuesto que el correlato de la revelación de Dios es todo ser humano por igual, siendo asi que, en la revelación de Dios, exisle una relación transcendental entre buena noticia y pobres22. Tener en cuenta a los pobres es, pues, condición necesaria para una evangelización que quiera ser ilustrada, y en ese sentido es un posible "principio de solución" a la crisis de evangelización. La solución no es mecánica, por supuesto, pero puede ser eficaz.

La segunda razón es de orden existencial. Como lo afirmó Puebla, los pobres lienen un potencial evangelizador. La convicción de que nosotros podemos evangelizar proviene en último lérmino de la experiencia de que nosotros somos evangelizados, lo cual puede ser también el mayor problema, pues eso expresa con loda claridad que la buena noticia es gracia y la antropología modema puede no saber qué hacer con la gracia. Los pobres son los que pueden "agraciarnos" y "evangelizarnos", y así hacernos a nosolros "agraciadores" y "evangelizadores".

22. A. Pieres, teúlogo cristiano asiảtico, buscando encontrar el potencial "universal" del cristianismo, to encuentra precisamente en la parcialidad. Esta parcialidad aparece, desde lo negativo, en que "Jcsús exprcsa la contradicción entre mammon (el dinero) y Yahvéh": y desde lo posilivo. en que "Jcsús encarna la alianza defensora entre los oprimidos y Yahvéh", Varios, Universalidad de Crisro. Universalidad del pobre, Santander 1995, p. 166, y esi parcialidad es la que abre a la universalidad. 
La realidad de los pobres, su modo de vivir y trabajar, de sufrir y celebrar, de creer y esperar, tiene algo que nos moviliza - aun teniendo en cuenta todas sus limitaciones y pecados. Por qué es esto así es su secreto. Tienen virtudes y tienen defectos, pero en la búsqueda y celebración de la vida, que no la dan por supuesta como la damos nosotros, tienen algo de bondad y de santidad cuasimetafísica con respecto a nosotros, los evangelizadores convencionales. "EI suertero que grita 'La de a mil', contiene no sé que fondo de Dios", dice Gustavo Gutiérrez, citando.a César Vallejo. En esos pobres, la divinidad está escarnecida, pero ahí está.

Es un hecho, atestiguado muchas veces. también ahora después de revoluciones fallidas: con los pobres y los márlires podemos caminar en la historia con esperanza. Machado inmortalizó el caminar en humildad: "caminante no hay camino, se hace camino al andar". Desde Amćrica Latina, don Pedro Casaldáliga lo ha reinterpretado con esperanza: "Haz del canto de lu Pueblo el ritmo de tu marchar". Y entonces, caminando así, hay esperanza. Se puede anunciar una buena noticia. 